\title{
PREFACE: THE 2ND EWAS INTERNATIONAL CONFERENCE ON EFFICIENT \& SUSTAINABLE WATER SYSTEMS TOWARD WORTH LIVING DEVELOPMENT
}

This special issue includes further elaborated papers from the "2nd International Conference on Efficient \& Sustainable Water Systems (EWaS) toward Worth Living Development," which covered applications and research in contemporary and traditional technologies such as environmental engineering, especially in relation to particle transport and deformable porous bodies, environmental heat transfer and flow, and characterization of porous media.

The EWaS series of conferences started in 2013, when the first EWaS conference was held in Thessaloniki, Greece. The second EWaS conference (EWaS2), held in Platanias/Chania, Crete, was co-organized by the Civil Engineering Department, University of Thessaly, and the School of Environmental Engineering, Technical University of Crete (cochairmen: V. Kanakoudis, University of Thessaly, and G. Karatzas, Technical University of Crete; vice chairman: E. Keramaris, University of Thessaly). The next EWaS conference will be organized in 2018. This special issue contains seven peer reviewed papers selected from the papers presented at the EWaS2 conference.

Contained herein, for theoretical, numerical, and experimental studies, the article "Numerical Simulation of Convective Currents in Aquatic Canopies using a Macroscopic Model" by Tsakiri and Prinos investigates the effect of vegetation porosity on convective currents. The empirical relationships between permeability and porosity and between current velocity and porosity are derived. Macroscopic results are presented together with microscopic results and available experimental data (Zhang and Nepf, 2009). The current velocity, water temperature, and times when the flow becomes dominated by inertia and drag are compared and are found to be in good agreement. The present macroscopic model, which is less time consuming and simpler to use than the microscopic model, is found to be applicable for simulating convective currents in vegetated areas. Moreover, the empirical relationships that are derived can be used for further investigation.

In the article "A Study of Flow in Open Channels with Vegetation: Experiments and Numerical Models," Keramaris et al. used two-dimensional particle image velocimetry (PIV) and a numerical model (in the ANSYS-CFX environment) to experimentally and numerically investigate turbulent flow in an open channel with flexible vegetation. To simulate a porous bed, grass-like flexible vegetation beds ( 2 and $6 \mathrm{~cm}$ thick) were used. The vertical distributions of the velocities above the flexible vegetation for different total heights were evaluated. The results showed good agreement between the results of the experimental and numerical studies. Small differences were observed only in the case of the flexible vegetation of lower thickness for the maximum discharge and for the higher total flow depths. This was due to the fact that the major discharge and high total flow depth provide greater turbulence, which reduces the horizontal velocities over the vegetation bed such that the model overestimates the velocities in these cases.

The article "Uncertainties in Porous Flow Models" by Stevovic et al. aimed to estimate the deviations in the results of analysis when the values of the parameters in fluid mechanical models are uncertain, i.e., if their value varies in certain intervals. In this paper, special attention is dedicated to dam-accumulation cases. The results obtained by the utilized methodology suggest that it is possible to predict the deviations in the models' value in the case of presumed values of its arguments and also to determine the accuracy in determining the arguments in order to obtain a predefined value of the models' variation.

In the article "Numerical Study of Particle Transport in a River with a Lateral Harbor Basin," Savvidis et al. investigate the particle transport in a navigable river and its lateral harbor basin, focusing mainly on possible deposition issues that might be dangerous for the harbor's normal operations. The investigation of such phenomena is of great interest since it constitutes an important tool in the computation of technical parameters concerning the right planning and operation of harbors lateral to the main stream of a river.

The article "The Impact of the Instrument in Velocity Measurements in an Open Channel with Porous Bed" by Keramaris presents the results of the impact of the instrument (hot-film anemometry and PIV) on the velocity 
measurements in open channels with a porous bed, in which individual experiments with these two methods were conducted. Initially, experiments were performed using the hot-film anemometry method and then the PIV method in open channels with a porous bed under the same conditions. In the simulation of the porous bed the following materials were used: (1) a porous filter; (2) flexible vegetation; (3) a gravel bed; and (4) a bundle of rods with porous thickness $s^{\prime}=2 \mathrm{~cm}$ and porosity $\varepsilon=0.75$. Sixteen laboratory experiments were carried out; four for each case. The velocity distribution of the flow above the porous bed at different total water heights and the same channel slope was evaluated. The results showed that different instruments influence the velocity distribution of the flow, especially in the case of a bundle of rods. Regarding the velocity distribution, the results in the other cases (porous filters, flexible vegetation, and gravel bed) showed good agreement between these two methods.

In the article "Artificial Neural Network for Bed Load Transport Rate in Nestos River, Greece," Papalaskaris et al. present 68 pairs of stream flow rate and bed load transport rate measurements of the Nestos River. Beyond these measurements, the bed load transport rate was calculated using the Meyer-Peter and Müller (1948) formula, which is considered one of the most reliable formulas, in order to calculate the bed load transport rate. As is declared in the paper, the specific work concerns the particle (sediment) transport in a river. The research, which is based on the development and application of experimental measurements and mathematical models, is obviously related to environmental engineering issues and is within the aims and scope of the porous media area since is refers to particle (sediment) transport in a river. Thus, by the end of the procedure, it was possible to compare the calculated rate to the site-measured river bed load transport rate.

Finally, in the paper "The Influence of Different Types of Permeable Beds (Flexible Vegetation and Inflexible Bundle of Rods) in Gravity Currents," Keramaris performed experiments in a laboratory tank to investigate the effect of a permeable bed (flexible or inflexible) on the movement of gravity currents. The vegetation in the bed of the laboratory tank was simulated initially with grass to create flexible vegetation and then with a bundle of rods to create inflexible vegetation, using the same vegetation height $\left(h_{v}=10 \mathrm{~cm}\right)$ and vegetation density $\left(\alpha=0.20 \mathrm{~cm}^{-1}\right)$. The experiments were carried out in a laboratory tank in which a removable thick vertical partition separated the two fluids (clear water and well-mixed saltwater) with density differences of $2 \%, 4 \%$, and $6 \%$. After removal of the partition, the created gravity current was monitored using a high-definition digital video. The movement of the current was studied (i.e., distance covered, effect of the difference in density, and effect of the height of the vegetation). The experimental results are compared with the experimental data obtained by other researchers (Shin et al., 2004; Tanino et al., 2005).

The Guest Editor would like to thank the authors of the papers for their scientific contributions and the article reviewers for their time and effort in order to ensure the high standards for submitted manuscripts. The Guest Editor is grateful to Begell House (the Home of Sciences and Engineering) and its team for their work in the publication of this special issue. Also, the Guest Editor is grateful to the Editor-in-Chief of the journal, Kambiz Vafai, for his kind contributions throughout the entire process.

\section{REFERENCES}

Meyer-Peter, E. and Mller, R., Formulas for bed-load transport, Proc. 2nd Congress International Association of Hydraulic Research, Stockholm, Sweden, pp. 39-64, 1948.

Shin, J.O., Dalziel, S.B., and Linden, P.F., Gravity currents produced by lock-exchange, J. Fluid Mech., vol. 521, pp. 1-34, 2004.

Tanino, Y., Nepf, H.M., and Kulis, P.S., Gravity currents in aquatic canopies, Water Resources Research, vol. 41, no. 12, W12402, 2005.

Zhang, X. and Nepf, H.M., Thermally driven exchange flow between open water and aquatic canopy, J. Fluid Mech., vol. 632, pp. 227-243, 2009.

\section{Guest Editor:}

Evangelos Keramaris

Assistant Professor, Civil Engineering Department

University of Thessaly, Volos, Greece

Special Topics \& Reviews in Porous Media — An International Journal 